\title{
Arang Aktif dari Ampas Kopi sebagai Absorben Logam Cu Terlarut dalam Skala Laboratorium
}

\author{
Asnita Fraselina Samosir*, Bambang Yulianto, Chrisna Adhi Suryono \\ Departemen IImu Kelautan, Fakultas Perikanan dan IImu Kelautan, Universitas Diponegoro \\ JI. Prof. H. Soedarto S.H, Tembalang,Semarang, Jawa Tengah 50275 Indonesia \\ ${ }^{*}$ Corresponding author, e-mail: asnitasamosir@gmail.com
}

\begin{abstract}
ABSTRAK : Pencemaran logam berat Tembaga $(\mathrm{Cu})$ di lingkungan perairan laut saat ini semakin meningkat. Logam berat ini memberikan dampak negatif bagi biota dalam perairan laut dengan menjadi penghambat pertumbuhan hingga menyebabkan kematian. Arang aktif dari ampas kopi dapat dimanfaatkan sebagai salah satu bioadsorben yang efektif. Penelitian mengenai penggunaan ampas kopi sebagai bioadsorben telah banyak dilakukan. Penelitian ini bertujuan untuk mengetahui kemampuan daya serap oleh arang aktif ampas kopi dengan lama perendaman dan konsentrasi yang berbeda terhadap logam berat Tembaga (Cu). Penelitian ini dilakukan pada tanggal 3 Juni 18 Juli 2018. Metode yang digunakan ialah metode eksperimental laboratoris. Aktivasi adsorben dilakukan menggunakan $\mathrm{HCl} \mathrm{0,1} \mathrm{M} \mathrm{selama} 48$ jam. Kemudian arang aktif dikeringkan pada suhu $110^{\circ} \mathrm{C}$ selama 3 jam untuk meningkatkan daya serapnya. Berdasarkan analisa Atomic Absorption Spectrophotometric (AAS) yang telah dilakukan diperoleh daya serap arang aktif dengan konsentrasi 0,5 gr, $1 \mathrm{gr}$, dan $2 \mathrm{gr}$ dengan masing-masing lama perendaman 15 menit, 30 menit, 60 menit, 90 menit, dan 120 menit berturut-turut adalah 99,28\%; 95,70\%; 98,79\%; 99,50\%; 97,98 \%; 95,39\%; 98,66\%; 99,46 \%; 99,92 \%; 97,04\%; 96,83\%; 98,57\%; 99,94\%; dan 99,96 \% dengan kecepatan pengadukan $150 \mathrm{rpm}$. Konsentrasi adsorben dan lama perendaman yang berbeda terhadap larutan logam $\mathrm{Cu}$ diketahui berpengaruh nyata terhadap penyerapan logam berat $\mathrm{Cu}$ $(p<0,05)$ oleh arang aktif. Terdapat penurunan daya adsorpsi arang aktif pada lama perendaman 30 menit kemudian tetap mengalami kenaikan daya adsorbsi terhadap logam Cu dengan semakin lama lama perendaman serta semakin tinggi konsentrasi adsorben yang digunakan.
\end{abstract}

Kata Kunci : logam berat $\mathrm{Cu}$, arang aktif, ampas kopi

\section{Activated Charcoal from Coffee Pulp as Absorbent of Dissolved Cu in Laboratory Scale}

ABSTRACT : Pollution of heavy metals Copper $(\mathrm{Cu})$ in the marine environment is currently increasing. This heavy metal has a negative impact on biota in marine waters by becoming a growth inhibitor that causes to death. Activated charcoal from coffee wastes can be used as an effective bio-adsorbent. Research on the use of coffee wastes as bio-adsorbent has been widely studied. This study aims to knowing the ability of activated charcoal from coffee wastes to absorb heavy metal of copper (Cu) using different immersion times and different concentrations of activated charcoal. The study was conducted on June 3 - July 18, 2018. The method used in this study was an experimental laboratory method. Activation of the adsorbent was carried out using $0.1 \mathrm{M} \mathrm{HCl}$ for 48 hours. Then the activated charcoal is dried at $110^{\circ} \mathrm{C}$ for 3 hours to improve the adsorption capacity of the adsorbent. Based on the analysis of Atomic Absorption Spectrophotometric (AAS), the absorption of activated charcoal has been obtained with concentrations of $0.5 \mathrm{gr}, 1 \mathrm{gr}$, and $2 \mathrm{gr}$ with contact time of 15 minutes, 30 minutes, 60 minutes, 90 minutes and 120 minutes are 99.28\%; 95.70\%; 98.79\%; 99.50\%; 97.98\%; 95.39\%; 98.66\%; 99.46\%; 99.92\%; 97.04\%; 96.83\%; 98.57\%; 99.94\%; and 99.96\% with a stirring speed of $150 \mathrm{rpm}$. The concentration of the adsorbent and the different immertion times for copper (Cu) solutions significantly affected the absorption of Cu heavy metals $(p<0.05)$ by activated charcoal. There was a decrease in activated charcoal adsorption power at the immertion time of 30 minutes and continued to increase the adsorption power of $\mathrm{Cu}$ metal with the longer immertion time and the higher the concentration of the adsorbent used.

Keywords : heavy metals Cu(II), activated charcoal, coffee wastes 


\section{PENDAHULUAN}

Tembaga $(\mathrm{Cu})$ merupakan salah satu logam berat dengan kadar yang meningkat di lingkungan perairan laut saat ini. Logam berat ini menjadi penghambat pertumbuhan hingga menyebabkan kematian biota perairan laut. Toksisitas Cu akan bekerja dalam tubuh organisme jika terdapat dalam jumlah yang besar atau melebihi nilai toleransi (Palar, 1994).

Kadar normal $\mathrm{Cu}$ dalam air laut berkisar antara 0.002-0.005 ppm (KLH, 2004). Kepentingan perikanan kurang dari $0.001 \mathrm{ppm}$, wisata bahari sebesar 0,05 ppm dan sebesar 0,008 untuk biota laut. Konsentrasi $\mathrm{Cu}$ terlarut dalam air laut sebesar 0,01 ppm dapat mengakibatkan kematian fitoplankton (Tarigan et al., 2003).

Penanganan kadar logam Tembaga dalam lingkungan perairan laut salah satunya ialah dengan metode adsorpsi yaitu penyerapan senyawa logam berat kedalam suatu bahan yang solid dengan reaksi kimia. Metode ini merupakan metode pengolahan limbah yang lebih baik dan efektif karena murah. Arang aktif dari ampas kopi adalah salah satu adsorben yang mudah ditemukan. Arang aktif ialah suatu padatan berpori yang mengandung 85-95\% karbon yang diperoleh dengan proses aktivasi untuk menghilangkan zat-zat pengotor pada permukaan arang sehingga dapat meningkatkan porositasnya (Allport, 1997).

Menurut Kyzas (2012), kadar optimum ampas kopi dalam mengadsorpsi $\mathrm{Cr}$ (VI) sebanyak 1,0 gram dalam 1 liter larutan $\mathrm{Cr}$ mampu mengadsorpsi krom (Cr) sebesar 90\%. Peneliti meningkatkan daya adsorpsi ampas kopi dengan cara aktivasi ampas kopi dan menjadikan dosis 1,0 gram sebagai acuan.

Tujuan penelitian untuk mengetahui kemampuan daya serap oleh arang aktif ampas kopi dengan lama perendaman dan konsentrasi yang berbeda terhadap logam berat Tembaga ( $\mathrm{Cu}$ ). Diharapkan hasil dari penelitian ini dapat dapat memberikan tambahan informasi kepada masyarakat mengenai manfaat ampas kopi dalam mengurangi pencemaran logam berat di perairan khususnya dan pada limbah domestik masyarakat umumnya.

\section{MATERI DAN METODE}

Ampas kopi sebanyak 1000 gram yang diperoleh dari kedai kopi dikeringkan dalam oven selama 5 jam pada suhu $105^{\circ} \mathrm{C}$. Selanjutnya dikarbonisasi menggunakan furnace pada suhu $600^{\circ} \mathrm{C}$ selama 4 jam dilanjutkan menghitung rendemen untuk mengetahui jumlah arang aktif yang dihasilkan. Selanjutnya dilakukan aktivasi secara kimia dengan perendaman larutan aktivator yaitu $\mathrm{HCl} 0,1 \mathrm{M}$ (Atmoko, 2012). Selanjutnya dicuci dengan air demineral hingga $\mathrm{pH} 6$ untuk menghilangkan sisa $\mathrm{HCl}$ didalam arang aktif ampas kopi. Selanjutnya dikeringkan dalam oven pada temperatur $110^{\circ} \mathrm{C}$ selama 3 jam.

Larutan logam berat Tembaga $(\mathrm{Cu})$ berasal dari senyawa $\mathrm{CuSO}_{4} \cdot 5 \mathrm{H}_{2} \mathrm{O}$ atau sering juga disebut cupric sulfat dengan $\mathrm{BA} \mathrm{Cu}=63,55 \mathrm{~g} / \mathrm{mol}$ dan $\mathrm{BM} \mathrm{CuSO}_{4} \cdot 5 \mathrm{H}_{2} \mathrm{O}=249,70 \mathrm{~g} / \mathrm{mol}$. Pembuatan larutan logam $\mathrm{Cu}$ diawali dengan pembuatan larutan stok dengan melarutkan 3,85 gram $\mathrm{CuSO}_{4} \cdot 5 \mathrm{H}_{2} \mathrm{O}$ dengan akuades untuk memperoleh konsentrasi $1000 \mathrm{mg} / \mathrm{L}$. Selanjutnya larutan diencerkan menjadi konsentrasi $30 \mathrm{mg} / \mathrm{L}$ (ppm).

Cara kerja perlakuan ini adalah merendam arang aktif ampas kopi pada sampel air laut sebanyak $50 \mathrm{ml}$ dengan kontaminasi logam $\mathrm{Cu}$ konsentrasi $30 \mathrm{ppm}$. Terdapat 4 perlakuan percobaan yaitu: 1) Perlakuan 1 sampel air tanpa perlakuan (kontrol), 2) Perlakuan 2, sampel air yang diberi arang aktif ampas kopi sebanyak $0,5 \mathrm{gr} / 50 \mathrm{ml}$, 3) Perlakuan 3, sampel air diberi arang aktif ampas kopi sebanyak $1 \mathrm{gr} / 50 \mathrm{ml}$, dan 4) Perlakuan 4, sampel air diberi perlakuan arang aktif ampas kopi sebanyak $2 \mathrm{gr} / 50 \mathrm{ml}$. Masing-masing perlakuan dipaparkan pada media air laut konsentrasi 30 ppm selama a) 15 menit, b) 30 menit, c) 60 menit, d) 90 menit, dan e) 120 menit dilakukan secara triplo. Selanjutnya sampel didiamkan selama 15 menit kemudian disaring menggunakan kertas saring. Setelah itu diberikan pengawet $\mathrm{HNO}_{3}$ kemudian diukur kandungan logam $\mathrm{Cu}$ dengan metode Atomic Absorption Spectrophotometric (AAS). Data hasil pengukuran kadar logam berat $\mathrm{Cu}$ diolah menggunakan software SPSS dengan metode Two Way ANOVA 


\section{HASIL DAN PEMBAHASAN}

Rendemen tahapan proses pembuatan arang aktif ini disajikan pada Tabel 1. Data hasil pengujian kadar tembaga (Cu) sampel air dengan menggunakan arang aktif ampas kopi sebagai bioadsorben pada larutan logam berat $(\mathrm{Cu})$ disajikan pada Tabel 2. Hasil analisa menunjukkan variabel kontrol memiliki kandungan logam berat $\mathrm{Cu}$ dengan konsentrasi sebesar $60,08 \mathrm{mg} / \mathrm{L}$. Hasil pengujian menunjukkan tingkat penyerapan logam berat yang relatif berbeda $(p<0,05)$ pada masing-masing konsentrasi arang aktif terdapat pada Tabel 3.

Perbedaan lama perendaman arang aktif dengan konsentrasi berbeda dengan media larutan logam berat $(\mathrm{Cu})$ menunjukkan tingkat penyerapan logam berat $\mathrm{Cu}$ yang berbeda secara signifikan $(p<0,05)$. Hasil penyerapan logam berat $\mathrm{Cu}$ berdasarkan interaksi faktor konsentrasi arang aktif dan lama perendaman arang aktif menunjukkan tingkat penyerapan logam berat yang relatif berbeda secara nyata $(p<0,05)$.

Tabel 1. Penurunan berat ampas kopi setelah proses karbonasi dan aktivasi

\begin{tabular}{lcc}
\hline \multicolumn{1}{c}{ Tahap } & Massa Produk $(\mathrm{gram})$ & Rendemen $(\%)$ \\
\hline Awal & 1000 & 100 \\
Pengeringan & 480,58 & 48,058 \\
Karbonisasi & 83,28 & 8,328 \\
Aktivasi & 61,61 & 6,161 \\
\hline
\end{tabular}

Tabel 2. Kadar Tembaga (mg/L) pada Larutan Logam Tembaga setelah Perendaman menggunakan Arang Aktif

\begin{tabular}{cccc}
\hline \multirow{2}{*}{ Lama Perendaman } & \multicolumn{3}{c}{ Konsentrasi Larutan Arang Aktif } \\
\cline { 2 - 4 } & $0,5 \mathrm{gr}$ & $1,0 \mathrm{gr}$ & $2,0 \mathrm{gr}$ \\
\hline 15 menit & $0,43 \pm 0,06$ & $1,22 \pm 0,70$ & $1,78 \pm 0,35$ \\
30 menit & $2,59 \pm 0,28$ & $2,77 \pm 0,34$ & $1,91 \pm 0,13$ \\
60 menit & $0,73 \pm 0,17$ & $0,80 \pm 0,23$ & $0,86 \pm 0,09$ \\
90 menit & $0,30 \pm 0,26$ & $0,33 \pm 0,17$ & $0,04 \pm 0,03$ \\
120 menit & $0,17 \pm 0,05$ & $0,05 \pm 0,01$ & $0,03 \pm 0,04$ \\
\hline
\end{tabular}

Tabel 3. Daya Serap Arang Aktif terhadap Logam Berat Tembaga (Cu)

\begin{tabular}{|c|c|c|c|}
\hline Parameter & Kosentrasi & Lama Perendaman & \% Penyerapan Tembaga (Cu) \\
\hline & $0,5 \mathrm{gr}$ & 15 menit & $99,28 \pm 0,13$ \\
\hline & & 30 menit & $95,70 \pm 0,48$ \\
\hline & & 60 menit & $98,79 \pm 0,26$ \\
\hline & & 90 menit & $99,50 \pm 0,42$ \\
\hline & & 120 menit & $99,72 \pm 0,07$ \\
\hline & $1,0 \mathrm{gr}$ & 15 menit & $97,98 \pm 1,13$ \\
\hline & & 30 menit & $95,39 \pm 0,55$ \\
\hline \multirow[t]{8}{*}{ Konsentrasi $\mathrm{Cu}$} & & 60 menit & $98,66 \pm 0,43$ \\
\hline & & 90 menit & $99,46 \pm 0,31$ \\
\hline & & 120 menit & $99,92 \pm 0,02$ \\
\hline & $2,0 \mathrm{gr}$ & 15 menit & $97,04 \pm 0,52$ \\
\hline & & 30 menit & $96,83 \pm 0,19$ \\
\hline & & 60 menit & $98,57 \pm 0,18$ \\
\hline & & 90 menit & $99,94 \pm 0,06$ \\
\hline & & 120 menit & $99,96 \pm 0,07$ \\
\hline
\end{tabular}


Hasil uji daya serap arang aktif dari ampas kopi yang telah dilakukan diperoleh persentase logam berat yang mampu diserap rata-rata diatas $95 \%$. Terdapat dua faktor perlakuan yang diujikan yakni konsentrasi arang aktif dan lama perendaman arang aktif dengan larutan logam Cu. Masing-masing faktor perlakukan memperoleh pengaruh yang signifikan terhadap penyerapan logam berat $\mathrm{Cu}$. Dari hasil uji yang dilakukan diperoleh adsorben yang paling tinggi menyerap logam Cu adalah konsentrasi 2,0 gram pada lama perendaman 120 menit sebesar 99,96\%. Sementara yang paling rendah pada konsentrasi 1,0 gram dan lama perendaman 30 menit sebesar 95,39\%. Proses penyerapan adsorbat oleh adsorben berlangsung sangat cepat pada menit ke-15 sementara logam berat yang terserap menurun pada menit yang ke-30 dan kembali meningkat terus pada menit berikutnya, setelah dikontakkan selama 120 menit efisiensi adsorpsi cenderung tidak terlalu banyak menyerap lagi. Terutama pada konsentrasi adsorben $2,0 \mathrm{gram}$. Hal ini disebabkan oleh semakin lama lama perendaman antara adsorbat dan adsorben maka pori-pori adsorben yang semula kosong akan terisi penuh sehingga menyebabkan jumlah adsorbat yang teradsorp oleh adsorben pada waktu tertentu akan mulai memasuki keadaan statis atau dengan peningkatan yang relative rendah.

Berdasarkan hasil olah data yang diperoleh konsentrasi paling efektif arang aktif untuk menyerap logam aktif adalah konsentrasi 2,0 gram dengan lama perendaman 90 menit. Hal ini kurang sesuai dengan penelitian yang dilakukan oleh Kyzas (2012), bahwa kadar optimum ampas kopi dalam mengadsorpsi $\mathrm{Cr}(\mathrm{VI})$ sebanyak 1 gram dalam 1 liter larutan $\mathrm{Cr}$ mampu mengadsorpsi krom ( $\mathrm{Cr}$ ) sebesar 90\%. Dimana peneliti meningkatkan daya adsorpsi ampas kopi dengan cara aktivasi ampas kopi dan menjadikan dosis 1 gram sebagai acuan. Aktivasi dilakukan dengan pemanasan pada temperatur tinggi dan penambahan larutan kimia sehingga memperluas permukaan arang aktif tersebut. Hal ini bisa jadi disebabkan oleh human error saat pengujian.

Hasil uji Duncan yang telah dilakukan diperoleh nilai $F$ hitung dari interaksi antara kedua faktor perlakuan adalah $0,02(p<0,05)$. Oleh karena itu penelitian ini dapat disimpulkan bahwa lama perendaman serta konsentrasi arang aktif berpengaruh nyata terhadap penyerapan logam berat disamping masing-masing variabel ini berpengaruh nyata terhadap adsorpsi logam $(\mathrm{Cu})$.

\section{KESIMPULAN}

Berdasarkan hasil penelitian, dapat ditarik kesimpulan bahwa nilai daya serap arang aktif dengan konsentrasi 0,5 gr, $1 \mathrm{gr}$, dan $2 \mathrm{gr}$ dengan masing-masing lama perendaman 15 menit, 30 menit, 60 menit, 90 menit, dan 120 menit berturut-turut adalah 99,28\%; 95,70\%; 98,79\%; 99,50\%; 97,98\%; 95,39\%; 98,66\%; 99,46\%; 99,92\%; 97,04\%; 96,83\%; 98,57\%; 99,94\%; dan 99,96 \% dengan kecepatan $150 \mathrm{rpm}$. Interaksi antara konsentrasi adsorben dengan lama perendaman dengan larutan logam $\mathrm{Cu}$ berpengaruh nyata terhadap penyerapan logam berat $\mathrm{Cu}$ oleh arang aktif.

\section{DAFTAR PUSTAKA}

Allport, H.B. 1997. Activated Carbon. Encyclopedia of Science and Technology. Mc Graw Hill Book Company. New York.

Atmoko, R.D. 2012. Skripsi: Pemanfaatan Karbon Aktif Batu Bara Termodifikasi TiO2 pada Proses Reduksi Gas Karbon Monoksida (CO) dan Penjernihan Asap Kebakaran. Fakultas Teknik, Universitas Indonesia, Depok.

Kyzas, G.Z. 2012. Commercial Coffee Wastes as Materials for Adsorption of Heavy Metals from Aqueous Solutions. Article Materials Vol.5.

Nazir. 1988. Metode Penelitian. Ghalia Indonesia, Jakarta.

Palar, H. 1994. Pencemaran dan Toksikologi Logam Berat. PT Rineka, Jakarta.

Tarigan, Z., Edward \& Rozak, A. 2003. Kandungan Logam Berat Pb, Cd, Cu, Zn dan Ni dalam Air Laut dan Sedimen di Muara Sungai Membramo, Papua dalam Kaitannya dengan Kepentingan Budidaya Perikanan. Makara Sains 7(3):119-127 